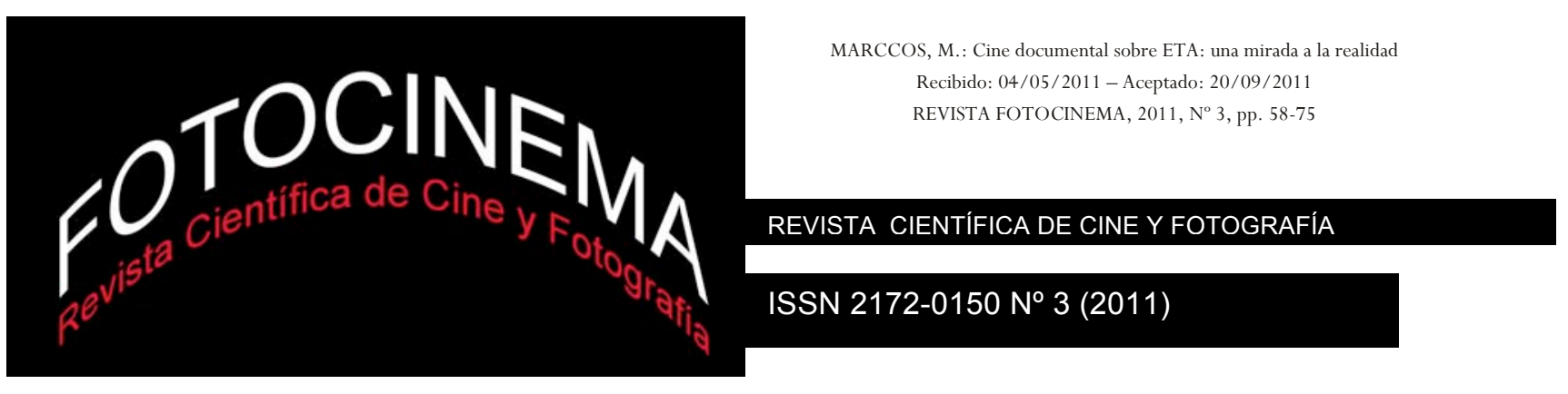

\title{
CINE DOCUMENTAL SOBRE ETA: UNA MIRADA A LA REALIDAD
}

\section{DOCUMENTARY CINEMA ON ETA: A LOOK TO THE REALITY}

\author{
María Marcos Ramos \\ Universidad de Salamanca
}

\section{Resumen:}

El presente artículo pretende ser una compilación de los documentales realizados sobre el terrorismo de ETA. El género documental recrea la realidad y es gracias a estos títulos, a la visión de sus creadores, como podemos acercarnos a una realidad que preocupa no solamente a las autoridades, sino también a los ciudadanos. En este artículo se analizarán los documentales más importantes realizados sobre el tema. Se hablará sobre el proceso de creación, la realidad narrada y las consecuencias que su realización supuso para sus realizadores y protagonistas. Iñaki Arteta, Julio Medem, Imanol Uribe o Eterio Ortega, entre otros, han tratado el conflicto etarra desde el género documental y han hecho de un tema tabú y difícil de abordar el leit-motiv de sus trabajos.

\begin{abstract}
:
This article is intended as a compilation of documentaries about terrorism of ETA. The documentary recreates the reality genre and it is thanks to such securities, the vision of its creators, how can we approach a situation which concerns not only the authorities but also to its citizens. This article will discuss the most important documentaries made about it. The article will discuss the process of creating the reality and the and the consequences of their realization. consequences narrated accounted for some of the filmmakers and stars of the same, their realization. Iñaki Arteta, Julio Medem, Imanol Uribe, Eterio Ortega, among others, have treated the conflict ETA from the documentary genre and have made a taboo subject and difficult to address, the leitmotif of their work.
\end{abstract}

\section{Palabras clave:}

ETA; cine documental; terrorismo; Imanol Uribe; Julio Medem

Key words:

ETA; documentary film; terrorism; Imanol Uribe; Julio Medem 


\section{Introducción}

No han sido muchos los directores que se han atrevido a abordar un tema tan interesante y con tantos matices como es el del terrorismo etarra. Es un tema espinoso, duro y conflictivo, que no deja indiferente a nadie y que puede causar, incluso, daños personales a quienes se han acercado a él de manera profesional ${ }^{1}$. Iñaki Arteta, uno de los que más veces se han tratado el tema, se ha mostrado sorprendido de que "un tema con unas posibilidades dramáticas tan interesantes y variadas, si hablamos de la ficción, o una realidad tan apasionante y dramática desde el lado del documental, no lo aborde más gente” (Arteta, 2005). Al margen de la particularidad y complejidad de la cuestión, el terrorismo etarra no ha sido un tema muy utilizado en el cine ${ }^{2}$. Ha habido directores que se han acercado a él en varias ocasiones, como Imanol Uribe o Iñaki Arteta; otros, como Julio Medem, solo lo han hecho en una ocasión. Algunos lo han hecho desde la ficción, ya sea recreando un hecho real o utilizando el terrorismo para crear una historia. Otros han utilizado el género documental para mostrar una realidad que, según las distintas encuestas del CIS, es un tema que preocupa a la mayoría de los españoles.

Tal y como señala Jean Baudrillard (2002), "al igual que un virus, el terrorismo está en todos lados. Hay un goteo permanente de terrorismo en el mundo: es la sombra que proyecta todo sistema de dominación listo a despertar en cualquier lugar como un agente doble. Ya no existe una línea de demarcación que permita cercarlo. Se halla en el corazón mismo de la cultura que lo combate”. Es un tema

\footnotetext{
1 Una situación parecida, o incluso peor, han vivido los medios de comunicación que se han atrevido a mostrarse contrarios a ETA, al igual que muchos otras personas. Tal y como señalan Fernando Delgado y José María Torre Cervigó en la introducción del libro Terrorismo, víctimas y medios de comunicación (2004: 14), "no olvidemos que informar en España sobre terrorismo implica estar amenazado permanentemente por los terroristas, porque ETA, en más de un comunicado, ha dirigido su dedo acusador hacia los periodistas y los medios de comunicación que le son beligerantes, es decir, a todos menos a unos pocos que todo el mundo conoce".

2 Análogo panorama presenta en el mundo de la literatura. Con la excepción que representan autores como Antonio Muñoz Molina -Plenilunio (1997)-, Fernando Aramburu -Los peces de la amargura (2006) o El vigilante del fiordo (2011)-, Jorge M. Reverte -Gálvez en Euskadi (1982) y Gudari Gálvez (2005)-, Bernardo Atxaga -El hombre solo (1993) y Esos cielos (1995)-, Raúl Guerra Garrido -La soledad del ángel de la guarda (2007)- o José Javier Abasolo -El aniversario de la independencia (2005)-, ha habido muy pocos escritores que hayan abordado el tema del terrorismo etarra en su narrativa.
} 
de primer orden que afecta a la sociedad, no solo a la vasca, sino a toda la sociedad, pero además es un tema complicado, difícil de solucionar, de entender y de convivir con él. No cabe duda de que el terrorismo es una materia polémica sobre la que no se puede frivolizar ni tratar sin atender a su extrema complejidad ya que, por ejemplo, "es posible que a mucha gente no le apetezca ver en el cine la parte humana del terrorista porque para ellos son demonios" (Carmona, 2004: 30). En este sentido se ha pronunciado Iñaki Arteta, realizador de varios documentales sobre las víctimas del terrorismo, al señalar que "la mayoría de las películas han demostrado una gran falta de sensibilidad. Muy a menudo se ha puesto el foco en las peripecias de los terroristas y la persecución policial. Incluso se han mostrado con cierta compresión a los etarras y hasta con algo de simpatía” (Alarcón, 2008).

Trasladar la realidad terrorista a la pantalla cinematográfica no es tarea fácil. Representar esta realidad, su complejidad, sus matices, la continuación de la vida tras la muerte no es sencillo ni muchas veces posible, pues, como se cuestionan Nekane Parejo Jiménez y Agustín Gómez Gómez3 (2003: 357), “¿debe existir el cadáver fotografiado para ver la muerte representada?”. Así, el conflicto etarra ha sido llevado al cine desde tres perspectivas: como documental, como centro argumental de la historia o como fondo sociohistórico. Son tres formas diferentes, pero igual de legítimas a la hora de reflejar realidades, crear ficciones referenciales y, en general, acercarnos a la historia más reciente de nuestro país.

A través de este artículo, se pretende compilar la diversidad de formas, temas y motivos de los documentales que han abordado el conflicto etarra. Es, pues, un repaso descriptivo y diacrónico a través del que se puede observar cómo el género ha ido evolucionando a medida que lo ha hecho la problemática del terrorismo y, especialmente, el modo en el que la sociedad ha reaccionado ante él y ha interpretado la posición tanto de los activistas de ETA como de sus víctimas. Asimismo, al contrastar los diversos filmes documentales puede observarse cómo con el paso del tiempo de la preocupación por la identidad nacional vasca -y por la represión a la que fue sometida durante el franquismo-

3 A pesar de que el artículo al que se refiere la cita es de fotografía, hay ciertas ideas, cómo las referidas a la representación de la muerte, que se pueden extrapolar a la imagen en movimiento. 
se ha pasado a una sensibilización hacia las consecuencias de la violencia y la barbarie.

\section{Documentales sobre ETA}

Frente a las ficciones, el documental "restituye la realidad, que muestra o describe, sin inferencia alguna del realizador -idealmente con asepsia científicauna realidad existente-" (Sánchez Noriega, 2002: 115). El conflicto etarra ha tenido una notable importancia en el género documental con casi una quincena de producciones sobre el tema. El primer documental que se realizó sobre el tema se gestó después de morir Franco, en plena transición y coincidiendo con el auge de la actividad etarra. Muchos de estos documentales trataban más de la denominada identidad nacional vasca que de la banda etarra, como puede ser Ama Lur4 (1966), de Néstor Basterretxea y Fernando M. Larruquert. Nos centraremos en este artículo en los documentales que traten la realidad etarra y no en los que hablen de la identidad vasca.

Después de morir Franco y en plena transición política, algunos directores se atrevieron a hablar del tema. El primero en expresar su visión del conflicto fue Iñaki Núñez con su cortometraje Estado de excepción 5 (1977). Ni la producción ni la realización estuvieron exentas de polémica. Tanto el director como parte de su equipo fueron detenidos y encarcelados, el rodaje parado y la productora, Araba Films, precintada. De hecho, Iñaki Núñez "se verá acusado de apología del terrorismo" (Aizarna, 1989: 174). Núñez realizó un filme de montaje, utilizando fotos fijas y también imágenes del cuadro el Gernika de Picasso. Estableció una relación entre la lucha de los vascos en la Guerra Civil y el

\footnotetext{
${ }^{4}$ Ama Lur fue estrenada en el Festival de Cine de San Sebastián en 1968 y desde hace décadas se considera la película fundacional del denominado "cine vasco". Aunque es una película vinculada con el problema de la identidad vasca $-\mathrm{y}$, por ello, determinados sectores de la crítica la relacionan con el conflicto- no hay alusiones al terrorismo en ella, entre otras cosas porque la actividad violenta de ETA en la época de su producción era casi insignificante. El principal objetivo de los autores fue, según ellos mismos afirmaron, dar a conocer Euskadi a sus propios habitantes, y ensalzar las señas de identidad del pueblo vasco. Ama Lur, película adscrita al género documental, ofrece una visión épica y triunfalista. De incisivo tono romántico, se centra en la valoración más tradicional del mundo rural como base de la cultura y de la sociedad de las siete provincias vascas.

5 Estado de excepción narra la historia de una familia vasca marcada por la Guerra Civil y la dictadura: el padre muere durante el bombardeo de Gernika y el hijo, cuando crece, se afilia a ETA y, tras ser detenido, es torturado y fusilado por la policía franquista.
} 
terrorismo de ETA, de modo que "su simplificación de los hechos históricos estaba presente en la continuidad absoluta del binomio Guerra Civil-ETA, y Gernika era un símbolo nacionalista de la opresión del pueblo vasco, lo que explica que el padre muera en la guerra, precisamente en el bombardeo del 26 de abril" (Contreras, 2000: 10).

En 1970 se celebró en Burgos un juicio que condenó a muerte a dieciséis personas acusadas de asesinar a tres personas y de pertenencia a banda armada. Imanol Uribé, uno de los directores que más han tratado directa o indirectamente en sus películas el conflicto vasco, decidió llevar este acontecimiento al cine bajo formato documental. Para ello, entrevistó a los acusados y a sus abogados7 acumulando más de veinte horas de material grabado. Sus declaraciones fueron apoyadas visualmente con la utilización de numerosos recortes de prensa que, a modo de foto fija, sirvieron para que el espectador entendiera el orden secuencial de los hechos y para que se empapase del ambiente que se vivió en esos años en España. En esa intención de recrear la realidad cobran un valor imprescindible, debido a su carácter de exclusividad, las imágenes -en formato 16 reversible- que el director consiguió del despliegue de las Fuerzas de Seguridad durante el juicio, de la entrada y salida del público asistente a las sesiones diarias o de los propios imputados camino de la prisión. Localizadas en Londres y propiedad de la Agencia Visnews -al igual que el audio original del proceso-, esas imágenes supusieron uno de los mayores valores del documental, al tiempo que ayudaron a reforzar su valor referencial. De este modo, tal y como han señalado algunos estudiosos, "Uribe dirigió un documental imprescindible para entender una parte decisiva de la historia contemporánea vasca, además de realizar una brillante película que logra encandilar a crítica y público” (Roldán Larrera, 2004: 553).

Euskadi hors d'État (1983) y Terreur d'État au Pays Basque (2000) son dos aportaciones del estadounidense de origen irlandés Arthur McCaig al conflicto

\footnotetext{
${ }^{6}$ Imanol Uribe es autor de la denominada trilogía vasca, formada por El proceso de Burgos (1979), La fuga de Segovia (1981) y La muerte de Mikel (1983). A estas tres obras hay que añadir otras dos de temática relacionada como Días contados (1994) y Plenilunio (2000), títulos en los que el terrorismo sigue estando presente. De todas ellas, estaría adscrita al género documental El proceso de Burgos. La fuga de Segovia es una obra ficcional aunque se trate de la recreación de un hecho real. La película está filmada de tal manera que parece real, como si fuese un falso documental. Los otros títulos son obras ficcionales.

7 Entre las personas a las que se entrevistó se encuentra a Francisco Letamendia, Enrique Gesalaga, Jon Etxabe y Mario Onandía.
} 
etarra. En el primer documental narra la historia del País Vasco desde la Guerra Civil hasta el inicio de la etapa del gobierno socialista. Así,

el documental describe la historia del País Vasco desde una supuesta "independencia primitiva", representada por los Fueros, hasta su derogación en el siglo XIX, desgarrada por Francia y España. Tras la Guerra Civil (enfrentamiento entre los vascos y España) se analiza el exilio vasco y el fracaso del PNV en su oposición al franquismo, lo que explicaría el nacimiento de ETA. Con la llegada de la Transición y la victoria socialista de 1982, el problema vasco seguía vigente, debido a que el PSOE habría optado por el "camino represor”. El filme, a pesar de tener algunos puntos de interés, incide en una visión muy sesgada de la cuestión vasca, identificando al País Vasco con el nacionalismo y a éste con ETA, de modo que parece que el terrorismo hizo posible el fin de la dictadura. Se hace hincapié en la ruptura que provocó la Guerra Civil en la sociedad vasca y se valoran poco los logros democráticos alcanzados con el Estatuto de autonomía. El documental parece querer ponerse en un prudente término medio entre dos extremos igualmente violentos (ETA y el Estado español) para intentar una negociación que diera lugar al final de esas dos violencias. De hecho, la prensa nacionalista acogió con evidente entusiasmo este filme, lo que indica hacia qué lado oscilaba esta versión supuestamente aséptica desde el extranjero (De Pablo, Barrenetxea, 2006: 184).

Terreur d'État au Pays Basque supuso una continuación de su anterior proyecto y en él cobraron mayor importancia los aspectos políticos, como demuestra el interés que despiertan para su autor las acciones de los Grupos Antiterroristas de Liberación (GAL). Arthur McCaig "intentó dar una visión objetiva de la situación en el País Vasco, basándose en la idea de que, al ser un director extranjero y por tanto no implicado en el conflicto, era posible abordar la cuestión con imparcialidad” (de Pablo, Barrenetxea, 2006: 184). Sin embargo, ninguno de sus dos títulos fueron imparciales ya que, por ejemplo en Terreur d'État au Pays Basque "la denuncia del terrorismo practicado por los GAL es correcta, en contrapartida, la violencia de ETA queda casi justificada, a causa de 
esa página negra de la historia de la política española y francesa” (de Pablo, Barrenetxea, 2006: 185).

En 1999 se realizó el documental, con una ideología muy próxima a la izquierda abertzale, Jo ta $k e^{8}$ de Anne de Galzain. El documental se remonta a la abolición foral en el siglo diecinueve y cuenta la historia del conflicto vasco hasta el acuerdo de Estella o Lizarra de 1998. Tal y como señalan Santiago de Pablo e Igor Barrenetxea (2006: 187-188),

Jo ta ke es un documental muy sesgado, que enfoca el terrorismo de ETA como un problema nacional, que enfrentaría a Euskadi contra España y Francia. Para ello, silencia la existencia de un importante porcentaje de vascos no nacionalistas y minimiza las diferencias entre el nacionalismo moderado y el radical, convirtiendo a ETA en una organización que lucha por la «dignidad» del pueblo vasco (...) Jo ta ke presenta una continuidad absoluta entre la ETA del franquismo y la situación democrática posterior a 1978, incidiendo en los casos de torturas, en los GAL y en la política represiva de España y Francia, que justificarían la violencia de ETA, apoyada supuestamente por un movimiento de resistencia mayoritario en la sociedad vasca.

Ha sido significativa la colaboración entre Eterio Ortega y Elías Querejeta9. De este tándem de director y productor han nacido dos importantes documentales: Asesinato en febrero (2001) y Perseguidos (2004), así como numerosos reportajes para televisión como Ciudadanos Vascos (2001), A través de Euskadi (1998), Euskadi en clave de futuro (1998)... incluidos en el proyecto El ojo de la cámara $^{10}$.

\footnotetext{
8 "Jo ta ke" es una expresión que se podría traducir al español como "sin parar".

9 Cierra la trilogía realizada por Querejeta y Ortega el documental Al final del túnel-Bakerantza (2011) presentado en la $59^{\text {a }}$ Edición del Festival de Cine de San Sebastián. El documental, que aborda el final de la violencia de ETA, muestra el testimonio de seis personajes, entre los que hay una víctima de ETA y otra del GAL, la mujer de un preso, otro miembro de la banda que estuvo en la cárcel 14 años y un recluso que aún permanece encarcelado y un sacerdote.

${ }^{10}$ El ojo de la cámara es un proyecto desarrollado por Elías Querejeta en el que, a través de la realización de mediometrajes, se abordan diversos aspectos de la realidad española. Tal y como señala Querejeta en su web (http://www.eliasquerejeta.com) "se trata de acercar la mirada de la cámara a la realidad que nos pertenece, de la que formamos parte". En total, se han producido 15 películas documentales, entre los que pueden citarse: Restos de la noche, de Sergio Oksman; Ciudadanos vascos, de Eterio Ortega; Vivir sin ver, de José Echevarría; Traineras, de Eterio Ortega, A través de Euskadi, de Eterio Ortega; Aznar-Almunia, diario de una campaña, de Sergio Oksman y Nacho Pérez de la Paz; Aymara, de Juan Lucas; 100 años no es nada, de José F. Echeverría...
} 
Ciudadanos vascos fue realizado por Querejeta y Ortega en su intento de reflejar la cotidianeidad del País Vasco y su convivencia con la violencia. Para desarrollar el proyecto, se les planteó la idea a los principales partidos políticos, de tal forma que cada uno eligió a cinco militantes de base y posteriormente se hizo una selección para decidir quiénes aparecerían en la película. Finalmente, los protagonistas fueron tres mujeres -simpatizantes, respectivamente, del PSOE-PSE, de IU-EB y del PP- y tres hombres - uno de ellos adscrito a la órbita del PNV, otro a la de EA y el último, a la de $\mathrm{EH}^{11-}$, que van exponiendo en el documental cómo viven, cómo ven la actual situación en el País Vasco y cuál puede ser el camino que facilite el encuentro entre los diferentes enfoques políticos para llegar a una sociedad en la que todos tengan cabida.

Asesinato en febrero (2001) narra el atentado perpetrado por ETA al dirigente socialista Fernando Buesa y su escolta, el ertzaina Jorge Díez, cuando caminaban por el campus universitario de Vitoria. Elías Querejeta, siempre comprometido con los ideales de paz, diálogo y resolución del conflicto, comenzó a pensar en rodar este documental cuando escuchó por la radio la noticia:

Me enteré de la noticia a través de la radio de un taxi. Acababan de asesinar a dos ciudadanos. No pude evitar un grito. El taxista me miró a través del retrovisor y me preguntó de dónde era. Le dije que era vasco. Una semana después, quizá diez días, me dicté una orden: escribe lo que se te esté pasando por la cabeza (Carmona, 2004: 149).

Siguiendo la misma fórmula utilizada por otros documentalistas -entrevistas realizadas a protagonistas del conflicto "desde una perspectiva extraordinariamente íntima" (Malalana, 2006: 205)-, Asesinato en febrero añade las impresiones de un experto en la lucha antiterrorista que irá desentrañando el modo de operar de los terroristas. La única imagen "real" teniendo en cuenta que el resto es parte de un documental guionizado y montado con una intención determinada-, está tomada de los servicios informativos y corresponde a la del atentado que les costó la vida a Fernando Buesa y Jorge Díez. El resto de las imágenes del proyecto están realizadas con la

${ }^{11}$ Los personajes elegidos para dar su opinión sobre la realidad del País Vasco fueron Gotzon Arrieta, Sofía Iturriza, Javier Gárate, José Maria Llamosa, Maite Pagazaurtunda y Ana Zarobe. 
intención de profundizar en los sentimientos de las personas entrevistadas. En ese sentido, resulta significativa y de un gran valor dramático los escenas en las que participan los familiares de Fernando Buesa y Jorge Díez. A través de sus palabras y de sus gestos el espectador percibe que los asesinados son personas humanas, que no son parte de ninguna ficción, que su existencia es -ha sidoreal y que no son un simple nombre que añadir a una lista.

En el mismo año que se estrenó Asesinato en febrero se realizaría para la plataforma de televisión Vía Digital un documental que habla sobre "la resistencia civil en el País Vasco" (Zorrilla, 2001). José Antonio Zorrilla filma Los Justos (2001), un documental en el que filósofos, escritores, artistas, cineastas, representantes sindicales, políticos, sacerdotes... describen y condenan el ambiente de terror que se vive en el País Vasco y desentrañan las claves del compromiso ciudadano ${ }^{12}$. De este modo, con los testimonios y con imágenes de archivo se ofrece una mirada crítica y beligerante sobre la resistencia civil en el País Vasco.

En 2004, Ortega y Querejeta vuelven a retratar la triste y cruda realidad en la que viven algunos ciudadanos. Perseguidos relata el día a día de dos de ellos: Patxi Elola y José Luis Vela, concejales de las localidades guipuzcoanas de Zarautz y Andoain que han de vivir protegidos continuamente por escoltas. La dificultad y peligrosidad de su situación no solo les afecta a ellos, sino también a su entorno más cercano. Así, la cámara es cómplice y testigo de la vida diaria de estos dos ciudadanos, creando un documental en el que no importan tanto los aspectos técnicos como los sentimientos. Las entrevistas e imágenes que presenta la película son una parte muy importante, pero es la música la que juega un papel significativo, siendo un elemento perturbador al servicio del contraste entre la aparente normalidad de sus vidas y la verdadera atmósfera de inquietud y miedo que han de soportar. Al igual que en Asesinato en febrero, se incluyen escenas reales de los momentos inmediatamente posteriores al atentado que costó la vida al periodista José Luis de la Calle.

\footnotetext{
${ }^{12}$ Coincidencia o no, tres de los personajes que colaboraron en el documental fueron víctimas al poco tiempo la barbarie de la que hablaban. Tal y como señala Zorrilla (2011) en su web "tres de los participantes sufrieron la ira del nacionalismo casi de inmediato. A Jaime Larrínaga (pbtro.) lo echaron de Maruri, su parroquia. A Gorka Landáburu le voló la mano un paquete bomba y a Joxeba Pagazaurtundua lo mató ETA".
} 
Sin duda alguna, el documental que más polémica ha causado ha sido el dirigido por Julio Medem La pelota vasca. La piel contra la tierra ${ }^{13}$. El punto de partida del proyecto fue el de ofrecer diferentes miradas y opiniones sobre el conflicto vasco, tal y como reconoció el propio cineasta:

Lo primero que me planteé (...) fue abarcar el mayor número posible de voces diferentes, como una polifonía humana en la que cada cual cantara a su aire (...). Quería individuos hablando de su preocupación personal por un problema social como es el vasco (...). Me propuse dejar opinar a todas las partes posibles del espectro vasco para luego hacer alternar sus voces, creando la sensación de que podrían escucharse unas a otras, si quisieran, y sobre todo entenderse, también a si mismas" (Medem, 2004).

Pero algunos no quisieron ni escuchar, ni hablar, ni participar... Ante la negativa a formar parte del proyecto de, entre otros, la cúpula de ETA, los representantes del PP, diversos periodistas y algunos miembros del Colectivo de Víctimas del Terrorismo -como, por ejemplo, Fernando Savater, Jon Juaristi o Cristina Cuesta- la propuesta de Medem quedó coja, obligatoriamente coja, y no muestra todas las opiniones y reacciones que el problema del terrorismo etarra desata entre la población. El objetivo de hacer un retrato global del País Vasco contemporáneo, de lograr con la película que todos sus miembros quedasen representados, quedó malogrado así desde el inicio.

La fórmula utilizada por Medem a la hora de abordar su trabajo no distó de la de los anteriores realizadores. De esta manera, el director donostiarra entrevistó a más de 100 personajes de la vida pública relacionados con el País Vasco, entre los que figuraban políticos como Felipe González, Juan José Ibarretxe, Arnaldo Otegi, Xavier Arzalluz, Javier Madrazo o Eduardo Madina; creadores y artistas

\footnotetext{
13 El estreno del documental en el 51 Festival Internacional de Cine de San Sebastián y su posterior nominación a los premios Goya -con decenas de manifestantes portando pegatinas y pancartas en contra del director- pusieron de manifiesto la dificultad de abordar el tema sin ser criticado ni puesto en cuestión. Tal fue el nivel de críticas y acusaciones vertidas sobre el filme que el director donostiarra se vio obligado a enviar

una carta a los medios de comunicación para defenderse y exponer su visión de su trabajo, tachado de partidista, equidistante y permisivo con la actividad terrorista desde diversos sectores de opinión. Medem reiteró su "rechazo al terrorismo (...) rotundo, sin peros", declarando que su "solidaridad y apoyo humano hacia las víctimas del terrorismo es absoluto, sin precio y sin esperar algo a cambio" (Medem, 2004). Fue la suya una afirmación que parece obvia y que en su caso de Medem se volvió necesaria.
} 
como Bernardo Atxaga, Fermín Muguruza o Txetxo Bengoetxea; representantes de la cultura como Ramón Zallo, José María Satrústegi o Jean Gratien Haritschelhar; periodistas como Iñaki Gabilondo, Xabier Eguzkitze, Javier Angulo o Antonio Álvarez Solís y un largo etcétera en el que convivían familiares de víctimas de ETA con simpatizantes de la banda terrorista, individuos amenazados con antiguos militantes de la banda. Sin voz en off que las introduzca, la suma de todas sus opiniones genera un complejo y profundo coro que es, por un lado, un retrato de diversos sectores de población del País Vasco y de España y, por otro, un reflejo de la intención de Medem de abogar por el diálogo como medio de resolución del conflicto.

La recopilación de opiniones y miradas que se hizo en el rodaje de La pelota vasca. La piel contra la piedra -se utilizaron dos cámaras digitales para la realización de las entrevistas, que se hicieron a ritmo de dos o tres por día, dividiendo para ello el equipo de trabajo- quedó unida en el montaje final con imágenes de archivo, procedentes de informativos y de películas como Ama lur (Néstor Basterretxea y Fernando Larruquert, 1968), Around the worl with Orson Welles (Orson Welles, 1955), Operación ogro (Gillo Pontecorvo, 1979), Yoyes (Helena Taberna, 1997), Vacas (Julio Medem, 1992) y Días Contados (Imanol Uribe, 1994). Junto a la labor de montaje, resulta de suma importancia la elección del marco en que se realizan las entrevistas, pues Medem prefirió hacerlas en escenarios naturales, fuera de sus hogares o lugares habituales de ocio y trabajo:

Es como si no quisiera ver el problema en el escenario real donde ocurre, (...) sino sólo a las personas que aceptaban desplazarse hasta donde yo les esperaba, en esas localizaciones (de los alrededores), parajes naturales en los que parece que toda tensión entre humanos está fuera de lugar. La suma aleatoria de fondos (en bosques, campas, montes, acantilados) que ayudan a retratar la geografía vasca más primigenia, calada de sentimientos tan antiguos como inamovibles, me vino bien para mantener el ojo de pájaro y así persuadirme de que puedo ver el odio sin odiarlo (Medem, 2004).

Al igual que en algunas de las obras de Querejeta, merece especial atención también la música que acompaña a las imágenes del documental, encargada al 
cantautor vasco Mikel Laboa, quien cedió expresamente para el proyecto algunos de sus temas clásicos -como Txoria txori ${ }^{14}$, una de sus canciones más famosas, todo un himno en el País Vasco- grabados junto a la Joven Orquesta de Euskadi y el Orfeón Donostiarra.

Hay que destacar la labor de Iñaki Arteta, autor de varios documentales relacionados con el tema15: Material sensible (1988), Sin libertad (1991) ${ }^{16}$, Voces sin libertad (2004), Trece entre mil (2005) y El infierno vasco (2008). Es la suya una obra que gira en torno a las víctimas del terrorismo etarra ${ }^{17}$, convirtiéndole en el máximo exponente de este tema en el género documental. Estos trabajos vienen a rellenar el vacío que el cine contemporáneo español ha creado alrededor de las víctimas, convertidas en auténticas protagonistas de sus títulos, ya que "recoge[n] el sentir de los afectados por los atentados, de los familiares de los asesinados y de los perseguidos: políticos, profesores, artistas, etc. [y] el hilo conductor de las entrevistas se centra en la visión personal que cada uno de ellos tiene de la situación del País Vasco” (Malalana, 2006: 205).

En Trece entre mil (2005) reúne el testimonio de trece víctimas de ETA. Algunos permanecen vivos, pero con evidentes secuelas tras los atentados sufridos. En otros casos, se da voz a sus familiares, insistiendo en cómo se sienten, cómo han rehecho su vida tras sufrir el horror de la violencia y el drama de la pérdida, cómo se han visto sometidas al olvido por parte de la sociedad y de las instituciones. Y es que la mayoría de los entrevistados fueron sacudidos por el fanatismo etarra precisamente en la década de 1980, el más sanguinario

\footnotetext{
${ }^{14}$ La letra de esta mítica canción, breve pero sumamente intensa, es una de las más celebradas del músico vasco Mikel Laboa. "hegoak ebaki banizkio / neria izango zen, ez zuen alde egingo/ baina honela, ez zen gehiago txoria izando / eta nik, txoria nuen maite" ["Si le hubiera cortado las alas/ habría sido mío, / no habría escapado. Pero así, / habría dejado de ser pájaro. Y yo... / yo lo que amaba era un pájaro"].

15 En paralelo a sus proyectos cinematográficos, Iñaki Arteta ha publicado, junto a Alfonso Galletero, dos libros relacionados con el conflicto etarra: Olvidados (2006) y El infierno vasco (2009). Olvidados narra las historias personales, contadas en primera persona, de veinte víctimas del terrorismo de ETA de los años ochenta. El libro está prologado por Baltasar Garzón y Joseba Arregi. El libro El infierno vasco es un trabajo paralelo a la realización del documental y, de algún modo, lo complementa, pues en él se incluyen no solo los testimonios de los entrevistados en el documental, sino otros que fueron grabados para él pero se excluyeron del montaje final de este trabajo de investigación.

${ }^{16}$ Sin libertad es una ampliación de 50 minutos del cortometraje Material Sensible.

${ }^{17}$ Nada será igual (2010) es el título de otro documental de Iñaki Arteta que aborda el tema del terrorismo. En este caso no es el protagonista el etarra, sino el islámico ya que el documental trata sobre el atentado del 11-M y sus víctimas. Producido por la Asociación de Víctimas del Terrorismo, es el primer documental que aborda el atentado que sufrió al ciudad de Madrid y, por extensión, la sociedad española en marzo del 2004.
} 
periodo de actividad de la banda, época en la que no existía en la sociedad el sentimiento de unidad y solidaridad contra el terrorismo que comenzó a gestarse después del secuestro y asesinato de Miguel Ángel Blanco ${ }^{18}$ en 1997. Para sacar del olvido a estas víctimas, el director recurrió a los periódicos impresos de la época como fuente de información y utilizó también recortes de prensa como foto-fija en el montaje del documental para contextualizar y dar a conocer al espectador los hechos relatados. Resulta un recurso especialmente emotivo la utilización de imágenes personales de las víctimas -generalmente fotografías y videos caseros facilitados por las familias-, siendo ésta la primera ocasión en que se han usado. La utilización de estas imágenes logra que el espectador conozca de alguna manera a las víctimas y permita así poner rostro al drama, creando grandes dosis de empatía con el público.

El infierno vasco (2008) narra la experiencia vivida por algunos ciudadanos vascos que, por sus ideas, se han visto obligadas a vivir fuera del País Vasco, esto es, a exiliarse. La película documental ha sido rodada entre 2005 y 2008, en la que entrevistaron a decenas de implicados logrando unas 100 horas de material bruto. Así, en primera persona, un grupo muy heterogéneo de personas de toda condición política, económica y social (profesores, periodistas, ertzainas, artistas, políticos, amas de casa, sacerdotes...) cuentan al espectador su dolor por tener que abandonar su tierra, así como las razones por las que decidieron marchar.

Otro documental realizado sobre el tema es el de Pedro Arjona, Corazones de hielo (2007). Está producido por el escritor y periodista Jorge M. Reverte, uno de los escritores españoles que ha reflejado en su literatura el problema del terrotismo. A través de una serie de entrevistas a algunas de las víctimas de ETA, y con la tragedia Antígona ${ }^{19}$ de Sófocles como trasfondo, el documental deja traslucir, sin victimismo ni afán vengativo, la entereza de quienes se enfrentan a la barbarie del terrorismo.

\footnotetext{
18 Coincidiendo con el undécimo aniversario del asesinato de Miguel Ángel Blanco, Antena 3 realizó una miniserie, 48 horas (2008), que narra las últimas 48 horas de vida de Miguel Ángel Blanco, el concejal del PP asesinado el 12 de julio de 1997 a manos de la banda terrorista ETA. ${ }^{19}$ En la mitología griega, Antígona es hija de Edipo y Yocasta y es hermana de Ismene, Eteocles y Polinices. Acompañó a su padre Edipo (rey de Tebas) al exilio y, a su muerte, regresó a la ciudad. En el mito, los dos hermanos varones de Antigona se encuentran constantemente combatiendo por el trono de Tebas, debido a una maldición que su padre había lanzado contra ellos.
} 
Mención a parte merecen algunos trabajos realizados por las cadenas de televisión y para ser emitidos en la pequeña pantalla, como por ejemplo, el realizado por TV-3 ETA a la ciutat dels sants (2011) en el que se narra el atentado terrorista que sufrió la casa cuartel de la Guardia Civil de Vic en 1981. La producción está dirigida por Albert Om²0, quien realiza un seguimiento cronológico del drama: los primeros momentos de confusión y pavor, el rescate desesperado de las víctimas entre los escombros, el tenso funeral, la controvertida captura y muerte de dos de los etarras ... Las imágenes incluyen las declaraciones y reflexiones de personas que vivieron el dramático suceso, y de políticos que tuvieron que afrontarlo, como Jordi Pujol, Narcís Serra y, también, Àngel Colom. Otro trabajo realizado por la cadena catalana es Pluja seca. Mediadors internacionals al País Basc (2011). Dirigido por Gorka Espiau, el documental muestra la labor que realiza un grupo de mediadores internacionales para lograr que ETA anuncie la tregua del 10 de enero de 2010. Entre los entrevistados se encuentra el sudafricano Brian Currin, quien desvela en el documental que en 2008 fue amenazado a través de una carta en nombre de $\mathrm{ETA}^{21}$.

Especialmente interesante e importante, por las fechas en las que se realizó, fue el documental que el programa Documentos TV de RTVE dedicó a la militante etarra María Dolores González Kataraín, Yoyes, especialmente famosa por su deserción de la banda y posterior asesinato a manos de los que fueron sus compañeros. Yoyes $^{22}$ (1988) fue realizado por Baltasar Magro y aparecen, por primera vez, militantes de ETA a cara descubierta hablando sobre la organización y su funcionamiento.

Por su parte, la cadena pública de la Comunidad de Madrid, Telemadrid, ha elaborado un documental sobre los GAL. GAL: La guerra sucia contra ETA (2007) que abarca 15 años con sus distintas etapas: la primera, cuando entre

${ }^{20}$ A modo de anécdota, Albert Om es un periodista que trabajaba a apenas 150 metros del lugar del atentado y fue uno de los primeros que llegó al lugar del salvaje ataque, en el que fallecieron 10 personas, cinco de ellos eran niños, y 44 personas resultaron heridas, la mayoría de ellas eran civiles.

${ }^{21}$ El resto de protagonistas de Pluja seca son John Hume, William de Klerk, Alec Reid, Roelf Meyer, Brian Currin, Harold Good, Jonathan Powell, Alex Maskey, Peter Robinson, Pierre Hazan, Denis Haughey, Charles Villavicencio, Brandon Hamber, Mohammed Baba, Aubrey Lekwane, Paula Leyden, Juan José Ibarretxe, Rufi Etxeberriaa, Leopoldo Barreda, José Antonio Pastor, Jone Goirizelaia y Paul Ríos.

${ }^{22}$ Yoyes es uno de los trabajos más premiados de Televisión Española. En 1989 recibió la Ninfa de Plata del Festival de Montecarlo y el premio Ondas. 
1983 y 1987 comenzaron los atentados en el sur de Francia; la segunda, cuando se investigaron y salió a la luz la implicación de fuerzas policiales en esos atentados contra terroristas de ETA; y, la tercera, cinco años después, cuando las sentencias judiciales condenaron a la cúpula del Ministerio de Interior. El documental se basa en entrevistas a personas relacionadas con la trama grabadas como si fueran cámaras ocultas- y utilizan imágenes de las películas de Miguel Courtois, El lobo'23 (2004) y Gal (2006).

La cadena pública vasca, por su parte, también ha realizado documentales para la televisión sobre el terrorismo. En 2010, de hecho, presentaba la serie documental Erretratuak-Retratos sobre los atentados perpetrados por ETA hace diez años contra José Luis López de Lacalle, Jesus Mari Pedrosa y Juan Mari Jauregi. Tal y como señala la web de la cadena ${ }^{24}$,

para la construcción del guión se ha contado con el testimonio directo de sus viudas, amigos y compañeros de trabajo. Sus vivencias personales y anécdotas trazan el retrato de cada víctima destacando su perfil privado y más personal; su lado más rebelde, incorrecto y activista; sus principios éticos; $\mathrm{y}$, su manera de ser y de relacionarse con los demás (...) Esta serie documental pone así su énfasis en la persona por delante de cualquier otra consideración, incidiendo en su vida cotidiana y en su trayectoria vital.

Los documentales, diez en total, tienen una duración de 30 minutos en los que se retrata visualmente a los protagonistas a través de sus orígenes, de sus pueblos, de sus álbumes fotográficos, de sus familiares y amigos... Cabe destacar que no se utilizan imágenes del día en el que cada una de las víctimas sufrieron el atentado que cambiaría sus vidas. Con esta serie de documentales EITB quiere rendir su homenaje, con motivo del $10^{\circ}$ aniversarios, a las víctimas de los atentado cometidos por ETA en el País Vasco y Navarra en el año 2000.

\footnotetext{
${ }^{23}$ Lobo (2004) cuenta la vida de Mikel Lejarza, un agente secreto que logra infiltrarse en la banda armada entre 1973 y 1975, consiguiendo desestabilizar la organización. Una vez descubierto, debe huir y se somete a una serie de operaciones de estética, cambiando, incluso de identidad. El propio Mikel Lejarza participó activamente en la elaboración del guión. Por su parte, Gal (2006) cuenta la historia de dos periodistas que iinvestigan una trama de corrupción en la guerra sucia contra ETA.

24 Para más información, se puede consultar la página web del proyecto realizado por EITB en http://www.eitb.com/es/television/detalle/414364/etb-emitira-serie-documentales-victimaseta/
} 


\section{Conclusión}

Del repaso descriptivo que se ha hecho en las páginas precedentes, puede concluirse que la importancia que el terrorismo etarra tiene en el debate político y social no se ha visto correspondida por la atención del cine documental. Desde un punto de vista cuantitativo, son pocos los títulos realizados sobre esta problemática -algo que también puede observarse en el cine narrativo, con las lógicas excepciones que suponen filmes como, sin ánimo de exhaustividad, $L a$ fuga de Segovia (Imanol Uribe, 1981), Yoyes (Helena Taberna, 2000), Lobo (Miguel Courtuois, 2004), Todos estamos invitados (Manuel Gutiérrez Aragón, 2008) o Tiro en la cabeza (Jaime Rosales, 2008)-, a pesar de que, como ya ha sido dicho, ocupa de forma permanente los primeros puestos de las preocupaciones de los ciudadanos, a juzgar por las encuestas que sobre esta cuestión puntualmente realiza el CIS. Por lo que se refiere al aspecto cualitativo, del panorama expuesto en este artículo puede deducirse que los documentales sobre el terrorismo etarra han virado hacia una mayor atención a las víctimas centrándose en retratos humanos basados en entrevistas y recreaciones de relatos vitales-, así como hacia una apelación a la resolución pacífica y dialogada del conflicto armado. Frente al activismo y a la radicalidad política de los documentales realizados a finales de la década de 1970 y comienzos de la de 1980, los últimos títulos han abogado por una mirada serena y humanista a través de la que conciliar los diversos puntos de vista que hay sobre el tema. En ese sentido, es importante resaltar cómo algunos documentales se han convertido en uno de los pocos espacios públicos que permiten la convivencia de posturas, ideologías y posiciones encontradas sobre el tema, cumplimentando así una función de debate y reflexión social y demostrando que, como decía Jean Luc Godard, "el cine es un instrumento de pensamiento".

\section{Referencias bibliográficas}

AIZARNA, S. (1989). Doce años de cultura española (1976-1987). Madrid: Encuentro.

ARTETA, I. (2005). "Documental “Trece entre mil”, de Iñaki Arteta, aborda el terrorismo de ETA desde el punto de vista de las víctimas". Revista Guión Actualidad, Consultado el 10 de Agosto de 2011, en http://antalya.uab.es/guionactualidad/ 
BARRENETXEA, I. (2008). "La transición y ETA: La fuga de Segovia (1981)”. Quaderns de Cine: Cine i Transició (1975-1982), 2, pp. 25-32.

BAUDRILLARD, J. (2002). L'esprit du terrorisme. Paris: Éditions Galilée.

CARMONA, L. M. (2004). El terrorismo y E.T.A. en el cine. Madrid: Capitel.

CONTRERAS, S. de P. (2000). “¿Símbolo o mito? La memoria cinematográfica del bombardeo de Gernika”. Ikusgaiak, 4, pp. 59-74.

DE PABLO, S. y BARRENETXEA, I. (2006). "Del oasis vasco a la Euskadi resistente. El País Vasco en el cine documental extranjero”. El nacionalismo vasco: mitos, conmemoraciones y lugares de la memoria, UGARTE, J. (2006), Historia y política, núm. 15, pp. 171-190

MALALANA UREÑA, A. (2006). "ETA y el cine. Las fuentes de información de los profesionales del cine". Revista General de Información y Documentación, 16 (2), pp. 195-216.

MARTÍN ALARCÓN, J. (2008). Entrevista a Iñaki Arteta: "La mayoría de las películas sobre ETA han demostrado una gran falta de sensibilidad". Consultado el 10 de Agosto de 2011, en http://www.elmundo.es/elmundo/2008/11/o7/cultura/1226056845.ht $\mathrm{ml}$

MEDEM, J. (2004). “S.O.S. La pelota vasca. La piel contra la piedra”. El País, 30 de enero de 2004. Consultado el 10 de Agosto de 2011, en

http://www.juliomedem.org/filmografia/Files/SOS.pdf

MEDEM, J. (2004). La pelota vasca. La piel contra la piedra. Dossier de producción.

SÁNCHEZ NORIEGA, J.L. (2002). Historia del cine. Teoría y géneros cinematográficos, fotografía y televisión. Madrid: Alianza Editorial.

SOJO, K. (1997). “Acerca de la existencia de un cine vasco actual”. Sancho el Sabio Revista de cultura e investigación vasca, 7, pp. 131-140.

ROLDÁN, C. (1999). "El cine de Euskadi en los 90”. Sancho el Sabio: Revista de cultura e investigación vasca, 10, pp. 79-95.

ROLDÁN, C. (2004). "Paisaje después de la batalla. Una aproximación al cine vasco contemporáneo”. Revista Internacional de Estudios Vascos, 49 (2), pp. 551-595.

PAREJO, N. y GÓMEZ, A. (2004). “La muerte como representación”. Segundas Jornadas Imagen, Cultura y Tecnología, pp. 357-366.

TORRADO, S. (2004). "La evolución histórica acerca del concepto de cine vasco a través de la bibliografía”. Sancho el Sabio: Revista de cultura e investigación vasca, 21, pp. 183-210.

ZUNZUNEGUI, S. (1994). "El largo viaje hacia la ficción”. En Entre el documental y la ficción. El cine de Imanol Uribe, Jesús Angulo, Carlos F. Heredero y José Luis Rebordinos (eds.), 53-68, San Sebastián: Filmoteca Vasca-Fundación Caja Vital Kutxa.

VV.AA. (2003): Terrorismo, víctimas y medios de comunicación. Madrid: Fundación de Victimas del terrorismo. 


\section{Filmografía citada}

Around the worl with Orson Welles, Orson Welles, 1955

Ama Lur, Néstor Basterretxea y Fernando M. Larruquert, 1966

Estado de excepción, Iñaki Núñez, 1977

El proceso de Burgos, Imanol Uribe, 1979

Operación ogro, Gillo Pontecorvo, 1979

La fuga de Segovia, Imanol Uribe, 1981

Euskadi hors d'État, Arthur Mac Caig, 1983

La muerte de Mikel, Imanol Uribe, 1983

Vacas, Julio Medem, 1992

Días Contados, Imanol Uribe, 1994

Yoyes, Helena Taberna, 1997

A través de Euskadi, Eterio Ortega, 1998

Euskadi en clave de futuro, Eterio Ortega, 1998

Jo ta ke, Anne de Galzain, 1999

Plenilunio, Imanol Uribe, 2000

Terreur d'État au Pays Basque, Arthur McCaig, 2001

Asesinato en febrero, Eterio Ortega, 2001

Ciudadanos vascos, Eterio Ortega, 2001

Sin libertad, Iñaki Arteta, 2001

Los justos, José Antonio Zorrilla, 2001

La pelota vasca. La piel contra la piedra, Julio Meden, 2003

Lobo, Miguel Courtois, 2004

Perseguidos, Eterio Ortega, 2004

Trece entre mil, Iñaki Arteta, 2005

Gal, Miguel Courtois, 2006

Corazones de hielo, Pedro Arjona, 2007

El infierno vasco, Iñaki Arteta, 2010

ETA a la ciutat dels sants, Albert Om, 2011

Al final del túnel - Bakerantza, Eterio Ortega, 2011 